\title{
What's Wrong
}

\section{with the Nene in}

Hawaii?

Stephen Mills

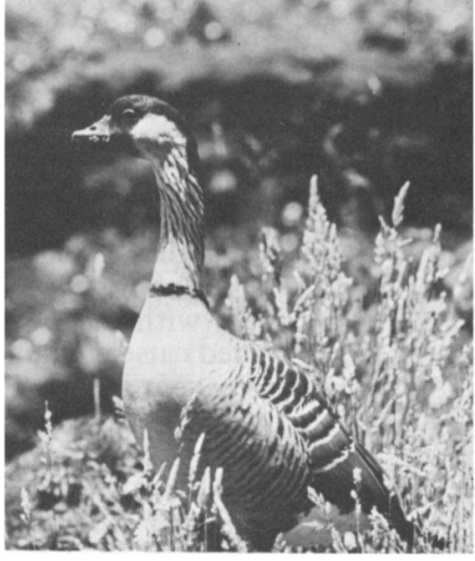

The author spent two months in 1977 studying conservation problems in Maui, in the Hawaiian Islands, especially those of the nene goose project. Captive breeding has been successful in saving this species, and over 400 birds have been released on Maui, but predation and habitat destruction by introduced goats, pigs, rats and mongooses are preventing the geese from building up these wild populations.

The story of the re-establishment of the nene Branta sandvicensis in Hawaii is a fairly familiar one. The Nene Propagation Project began in 1949. Captive birds were reared at Pohakuloa on the 'Big Island' of Hawaii, and two years later at the Wildfowl Trust at Slimbridge in England. The original birds, two pairs for Pohakuloa and one pair for Slimbridge, came from the only captive flock, owned by Herbert Shipman, a Hawaiian rancher. After ten years of reasonably successful breeding, Congress in 1956 endorsed a federal grant of $\$ 15,000$ annually, raised in 1968 to $\$ 25,000$, to help with the releasing scheme and the establishment of an independent breeding population in the wild.

The initial stages were well organised. Sites for the open-topped release pens, three on Hawaii and one on Maui, were carefully chosen; the birds were continually monitored for parasites visible in the faeces, and protected from predation; effective systems of natural incubation, double broods and gradual release were developed, and mortality in the pens was low. But, considering the care that has been taken to get birds to the release stage, the result so far has been disappointing.

The least successful release area appears to have been that on Maui. The pen was placed at Paliku, an undisturbed valley in the south-east corner of the
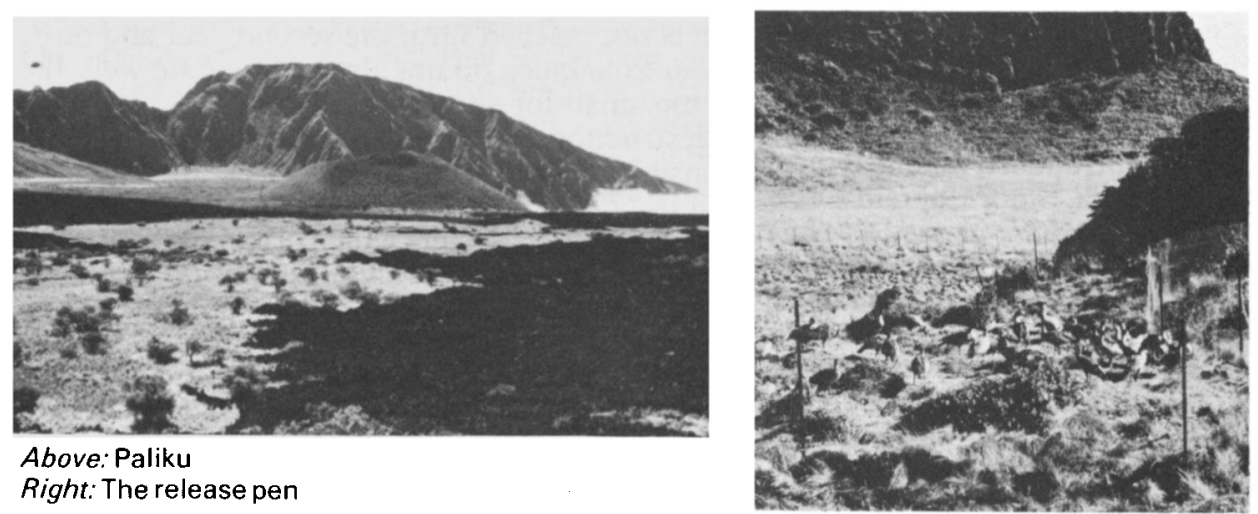
crater of the dormant Haleakala volcano, only half a mile from the ranger's cabin. The valley is particularly rich in suitable foods, mainly mesquite grass Holcus lanatus (known in Britain as Yorkshire fog), and mountain pili Panicum tenuifolium, with sheep sorrel Rumex acetosella, gosmore Hypochaeris radicata (long-rooted catsear), kukaenene Coprosma ernodeoides and puakeawe Styphelia tameiameiae; equally good are the $1000 \mathrm{ft}$ cliffs and grassland plateaus above the valley, where the birds that have survived in the wild now live.

Between 1962 and 1968 an average of about 25 birds were released each year. In 196972 birds were put out, bringing the total to 242, which it was hoped would suffice at Paliku. Unfortunately large new injections have been needed ever since: 44 in 1972, 50 in 1973, 34 in 1976, and in 1977 the 'final' release of 48.

And the results? Dr Janet Kear of the Wildfowl Trust, whose book on the nene, written with Professor Andrew Berger, is due to be published shortly, estimates from the available data and literature that there may be 150 nenes in Haleakala. My own observations in the summer of 1977 agreed with this figure. Edwin Andradi, the chief biologist with the Fish and Wildlife Service on Maui, was hesitant about the total, but he suggested that before the final release the proportion of 'wild' to captive-reared birds was about 50:50. However field research, hampered by the rugged terrain and the birds' shedding of their colour rings (bands) so that their status (captive or wild bred) and their year groups get confused, has been surprisingly scanty. In fact it is not known how many have bred, or whether the 'missing' 300 released birds have perished, been shot, or simply not been spotted in the more remote cliffs above the rain forests. Hopefully this lack of research will be rectified now that Paul Banko, an experienced researcher from the University of Oregon, has elected to do his doctorate on the wild nene. But it is a pity that the work was not started ten years ago.

The first wild Haleakala goslings were found in 1968. Since then breeding has been only sporadic and there appear to be no accurate data. The most successful breeding season, which is November to March, was in 1976-77; by the end of February 1977, at least four families had been reported. This comparative success may have been due, as Janet Kear suggested, to the unusually dry winter. Paliku is normally the wettest area of the crater and was selected more for its food abundance than its climate. But the nene long ago adapted to dry upland conditions and even lost part of the webbing on its feet, so one problem may be too much moisture. Perhaps, also, those few square miles of habitat available on Maui are too restricted to support a thriving wild population. As sexual maturity is not reached until the second year and birds from Slimbridge and birds from Pohakuloa do not always integrate well, the variety of individuals may be too small for successful mating.

But predation and habitat destruction are the most serious problems, and introduced mammals are responsible for both. Hawaii is a conservation disaster area. Since Captain Cook's visit in 1778, 25 species of bird have been hunted or otherwise harried to extinction. A fragile ecosystem which originally contained only one endemic land mammal, the Hawaiian bat Lasiurus semotus, has been swamped with feral dogs, cats, sheep, goats and pigs. Rats, mainly the brown Rattus norvegicus but also the black $R$. rattus and the Hawaiian race of the Polynesian $R$. exulans, came with the early settlers and have spread everywhere. In 1833 the Indian mongoose Herpestes auropunctatus was brought in to control the rats, but since the mongoose hunts mainly by day and the rats by 


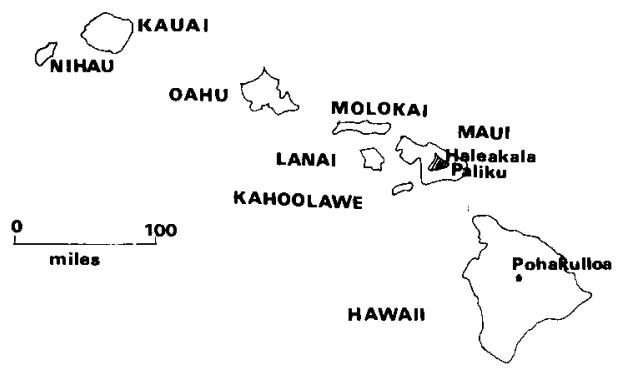

night the result was two major predators instead of one.

In Haleakala the problem is particularly acute. Feral goats are grazing away the nene's favourite grasses on the lonely plateaus where the birds are most likely to breed. Pigs root up the soil surface, spoiling the grasslands and eating any eggs they can find, and their faeces spread the seeds of mangoes and other introduced plant species into the old rain forests on the mountain's western slopes. David Dunatchik, Chief Ranger of the National Park, reckons that his rangers may shoot 50 pigs and about 250 goats each year, but it is not enough, as he admits. There is talk of federal funds being made available to fence the whole crater around the lower slopes - at least 40 miles of fencing that may cost about 3 million dollars. It may be the only solution.

Neither the rats that eat the eggs and nestlings nor the mongooses that kill the adults as well can be controlled by shooting. Jitsumu Kunioki, who is researching the dark-rumped petrel Pterodroma phaeopygia sandwichensis whose sole substantial colony in the world is in Haleakala, reports heavy rat predation in the nest holes, and is trapping them rather haphazardly. But to cover even the one major cliff site he will need thousands of traps and many more helpers. A much more serious trapping campaign should be mounted within the crater against both these predators.

Poison is another possible solution. Usually the federal authorities are, quite rightly, reluctant to use this. But Haleakala is not a usual case: so many unique bird and plant species are endangered here by pests, and there is only one endemic predator, the Hawaiian subspecies of the short-eared owl Asio flammeus sandwichensis, that might be endangered by the poison. The only other raptor, the Hawaiian hawk Buteo solitarius, is found solely on the big island of Hawaii. So the effects of a restrained use of poison could be monitored, and favoured breeding areas could be fenced with small-mesh wire for added protection.

Dr Kear estimates the world nene population at about 2000: 1000 in zoos, 198 in Wildfowl Trust sites, 600 on Hawaii and 150 on Maui. Captive breeding has saved the species, but that is not the same as re-establishing a wild population, which calls for diligent and professional research, and close attention to practical conservation needs and local conditions. As habitats diminish and the possibilities are reduced, re-establishment in the wild becomes increasingly urgent. It is simply not enough to release individuals and do a rough count every now and then. If a species is worth saving, it is worth saving properly.

\section{Acknowledgments}

The author wishes to thank the Agfa-Gevaert Company (England) for provision of film, and also the scientists mentioned in the article for providing information.

Stephen Mills, Suntrap, Forest Hill, Oxford, England. 